\title{
Therapeutic effect of methylprednisolone combined with high frequency electrotherapy on acute spinal cord injury in rats
}

\author{
SHUIQIN LI ${ }^{1}$, YAN OU ${ }^{2}$, CHAONAN LI $^{1}$, WEI WEI ${ }^{1}$, LEI LEI $^{1}$ and QIAOJUN ZHANG ${ }^{2}$ \\ ${ }^{1}$ Department of Rehabilitation Medicine, The First Affiliated Hospital of Xi'an Medical University, Xi'an, Shaanxi 710077; \\ ${ }^{2}$ Department of Nephrology, The Second Affiliated Hospital of Xi'an Jiaotong University, Xi'an, Shaanxi 710004, P.R. China
}

Received September 11, 2018; Accepted May 16, 2019

DOI: $10.3892 /$ etm.2019.8147

\begin{abstract}
Acute spinal cord injury (SCI) has a high rate of disability and mortality. Although secondary SCI results in local tissue hypoxia and the release of inflammatory mediators, it is both controllable and reversible. Therefore, timely rehabilitation treatment is beneficial for the partial recovery of patients with SCI. The present study aimed to investigate the use of methylprednisolone combined with high-frequency electrotherapy as a method of rehabilitation treatment in rats with SCI. The rat SCI model was prepared using the modified Allen's method with the animals randomly divided into the following 4 groups ( $\mathrm{n}=10$ for each group): SCI; methylprednisolone (300 mg/kg); high-frequency electrotherapy; and combination treatment with electrotherapy combined with methylprednisolone $(300 \mathrm{mg} / \mathrm{kg})$. The Basso, Beattie and Bresnahan (BBB) score, somatosensory evoked potential (SEP) and motor evoked potential (MEP) were used to assess spinal function. Brain-derived neurotrophic factor (BDNF) and $\mathrm{NF}-\kappa \mathrm{B}$ expression levels were detected using reverse transcription-quantitative PCR and western blotting. Tumor necrosis factor (TNF)- $\alpha$ and IL-2 expression levels were determined by ELISA, and caspase 3 activity was also assessed. In all treatment groups, BDNF mRNA and protein expression levels were significantly increased, whilst those of $\mathrm{NF}-\kappa \mathrm{B}$ were reduced. Additionally, an elevated BBB score, improved SEPs and MEPs, inhibited caspase 3 activity and downregulated TNF- $\alpha$ and IL-2 expression levels were observed, compared with the SCI group $(\mathrm{P}<0.05)$. However, the combination group exhibited more significant effects on SCI. In conclusion, methylprednisolone combined with high frequency electrotherapy may improve the symptoms of SCI by increasing the expression level of BDNF, reducing that of $\mathrm{NF}-\kappa \mathrm{B}$, and suppressing the secretion of inflammatory factors.
\end{abstract}

Correspondence to: Dr Yan Ou, Department of Nephrology, The Second Affiliated Hospital of Xi'an Jiaotong University, 157 West Fifth Road, Xi'an, Shaanxi 710004, P.R China

E-mail: shuoshang493@163.com

Key words: spinal cord injury, methylprednisolone, high-frequency electrotherapy, NF- $\kappa \mathrm{B}$, brain-derived neurotrophic factor, caspase 3

\section{Introduction}

Due to continuous progress in the construction and mining industries, and the development of the transportation industry, the number of accidental spinal cord injuries (SCIs) caused by crashes or car accidents has increased in recent years $(1,2)$. SCI often results in spasticity and dysfunction under the injured spinal cord segment, with characteristic high morbidity and mortality (3). Furthermore, due to the nature of their occupation, young adults $>40$ years if age are at high-risk (4). SCI treatment is challenging due to its high cost and invasiveness. SCI not only leads to physical and psychological damage to the patient, but also causes a notable economic burden $(5,6)$. SCI can be classified as primary or secondary in which primary injury can lead to local tissue damage, ischemia and hypoxia, inflammatory mediator release and pathological changes. Secondary lesions are more severe, and result from the cascade-amplification effects of primary injury. Secondary lesions can result in damage to residual neural pathways and further loss of function, but are both controllable and reversible $(7,8)$.

With advancements in medical treatment technology, the emergence of surgical methods and drugs has shown initial success in SCI treatment. Rehabilitation interventions cannot be neglected and are considered to promote spinal cord remodeling $(9,10)$. Different drugs are used to relieve pain in patients with SCI (11); methylprednisolone attenuates the peroxidation of membrane lipids and post-traumatic inflammation, and has consistently been associated with improved neurobehavioral outcome in preclinical studies (12). High-frequency electrotherapy, a non-invasive and inexpensive technique is also widely used for physical therapy to treat pain in SCI patients. Additionally, transcutaneous electrical nerve stimulation is the most commonly used electrotherapy method to relieve pain (13). However, the effect of methylprednisolone combined with high-frequency electrotherapeutic treatment on SCI and its associated mechanisms is yet to be elucidated. Therefore, the present study established a rat SCI model to analyze the impact and possible mechanisms of methylprednisolone treatment combined with high-frequency electrotherapy.

\section{Materials and methods}

Experimental animals. Healthy, specific pathogen free (SPF) grade male Wistar rats (2 months old; $250 \pm 20 \mathrm{~g}$ ) were 
purchased from the experimental animal center and maintained in the SPF Xi'an Medical University Animal Experimental Center. The animals were maintained at $21 \pm 1^{\circ} \mathrm{C}$, at a relative humidity of $50-70 \%$ and a $12 \mathrm{~h}$ day/night cycle. All procedures were approved by the Animal Ethics Committee of The First Affiliated Hospital of Xi'an Medical University.

Reagents and instruments. Pentobarbital sodium was purchased from Zhpharma Ltd. PVDF membranes were purchased from Pall Life Sciences. Western blotting-related chemical reagents were purchased from the Beyotime Institute of Biotechnology and enhanced chemiluminescence (ECL) reagents were purchased from GE Healthcare. Rabbit anti-BDNF and rabbit anti-NF- $\kappa \mathrm{B}$ antibodies, as well as sheep anti-rabbit horseradish peroxidase (HRP)-labeled IgG secondary antibodies were purchased from Abcam, Inc. Methylprednisolone was purchased from Sigma-Aldrich (Merck KGaA). Tumor necrosis factor (TNF)- $\alpha$ and IL-2 ELISA kits were purchased from R\&D Systems, Inc., and the Caspase 3 Activity Assay kit was purchased from Cell Signaling Technology, Inc. Microsurgical instruments were purchased from Suzhou Medical Instrument Factory. The RNA extraction kit and reverse transcription kit were purchased from Applied Biosystems (Thermo Fisher Scientific, Inc.). The Multi-Parameter Monitor Small Animal Physiology Monitor was purchased from Shanghai Yuken Instrument Company, and the Amp PCR System 2400 DNA Amplification System was purchased from PerkinElmer, Inc. The Imark microplate reader was purchased from BD Biosciences. Key-point evoked potential meters, electromyographs and Magpro magnetic stimulators were purchased from Dantec Dynamics. The UWM-02 Ultrashort Wave Therapy Instrument was purchased from Marubeni Corporation.

Animal grouping and treatment. The rats were randomly divided into four groups: SCI; methylprednisolone (300 mg/kg); high-frequency electrotherapy (treated with microwave irradiation from $7 \mathrm{~cm}$ at $10 \mathrm{w}$ for $10 \mathrm{~min}$ per day); and combination (treated with electrotherapy combined with $300 \mathrm{mg} / \mathrm{kg}$ methylprednisolone). $\mathrm{N}=10$ for each group.

SCI modeling. According to current literature, the rat SCI model was established using the modified ALLEN struck method (14). Following anesthetization using an intraperitoneal injection of $30 \mathrm{mg} / \mathrm{kg}$ sodium pentobarbital, the rats were immobilized on the operating table. The vertebral plates and spinous processes of the thoracic vertebrae (T9-T11) were removed. The center was set at the T10 spinal cord and a circular area with a diameter of approximately $4 \mathrm{~mm}$ was determined as the lesion area. According to the physiological curvature of the dorsal spinal cord of rats, pre-bent plastic flexion pads of $3 \mathrm{~mm}$ in length, $2 \mathrm{~mm}$ in width, and $1 \mathrm{~mm}$ thick were prepared. The pads were placed outside of the spinal cord in the T10 area. Using the modified ALLEN's striking device, the center was set in the median posterior of the spinal cord. The striker rod moves freely through the sleeve at a height of $5 \mathrm{~cm}$ and directly hits the plastic gasket. Signs of successful modeling include the body and lower extremities retracting and flapping, in additional to tail swing. The surgical incision was closed and antibiotics (Baytril ${ }^{\circledR}$; Bayer AG; 4 mg/kg subcutaneous) were routinely administered.
Collection of spinal cord tissues. Spinal cord tissues were collected as previously described (15). The rats were sacrificed using sodium pentobarbital to effect, and transcardially perfused with 0.1 M phosphate-buffered saline (PBS, $\mathrm{pH} 7.4$ ) followed by $4 \%$ paraformaldehyde (in PBS). To maintain consistency, each spinal cord was rostrally transected at the T6 spinal root, and a $3 \mathrm{~cm}$ segment of spinal cord was immediately dissected and fixed in paraformaldehyde for $2 \mathrm{~h}$ at $4^{\circ} \mathrm{C}$, followed by the relevant analysis.

Basso, Beattie and Bresnahan (BBB) scoring. On the 20th day after surgery, the BBB score was measured to evaluate the recovery ability of the joints and lower limbs. The score was 0-21 points; 0 points indicated no visible hind limb movement, and 21 points indicated continuous palmar movement, continuous coordination gait, continuous toe grip, the parallel position of the active paw to the body, continued trunk stability and tail tilt. A higher BBB score indicates improved recovery (12).

SEP and MEP measurement. At 20 days post-surgery, evoked potentials and electromyography were used to detect SEP and MEP. The rats were anesthetized and stabilized at the right iliac and the Achilles tendon. A DC square wave pulse current with a wave width of $0.2 \mathrm{msec}$ and a frequency of $2 \mathrm{~Hz}$ was selected. The test time was $20 \mathrm{msec}$, and a superposition range of $\pm 200 \mathrm{msec}$ was recorded. The current waveform P1 and an incubation period of N1 were recorded. The main electrode was placed in the muscle belly of the right gastrocnemius and the action potential was recorded using a magnetic stimulator with a test time of $0.2 \mathrm{msec}$.

Sample collection. On the 20th day after surgery, a total of $5 \mathrm{ml}$ blood was collected via the tail vein. The blood was centrifuged at $1,200 \mathrm{x} \mathrm{g} \mathrm{rpm}$ for $15 \mathrm{~min}$, and the serum was collected and stored at $-80^{\circ} \mathrm{C}$.

ELISA. TNF- $\alpha$ and IL-2 expression levels were detected by ELISA according to the manufacturer's protocol. A total of $50 \mu 1$ diluted standard or sample was added in triplicate to a 96 -well plate and incubated at $37^{\circ} \mathrm{C}$ for $1 \mathrm{~h}$. After washing five times, $50 \mu$ l enzyme-labeled reagent was added to each well and incubated at $37^{\circ} \mathrm{C}$ for $30 \mathrm{~min}$. The plate was subsequently treated with $50 \mu \mathrm{l}$ each of color agent $\mathrm{A}$ and $\mathrm{B}$ at $37^{\circ} \mathrm{C}$ for $10 \mathrm{~min}$. Finally, $50 \mu \mathrm{l}$ stop solution was added and the absorption at $450 \mathrm{~nm}$ was recorded using a microplate reader. The concentration of the sample was calculated and linear regression was compared with the absorbance value of the standard.

Caspase 3 activity. Caspase 3 activity in spinal cord tissue was determined using the Caspase 3 Activity Assay kit according to the manufacturer's protocol. Briefly, the cells were enzymatically digested and centrifuged at $600 \mathrm{x}$ g for $5 \min \left(4^{\circ} \mathrm{C}\right)$. The cells were subsequently treated with RIPA lysis buffer (Thermo Fisher Scientific, Inc.) on ice for $15 \mathrm{~min}$ and centrifuged at $20,000 \mathrm{x}$ g for $5 \mathrm{~min}\left(4^{\circ} \mathrm{C}\right)$. Absorbance was detected at $405 \mathrm{~nm}$ following the addition of $2 \mathrm{mM}$ Ac-DEVD-pNA to each test sample.

Reverse transcription-quantitative PCR (RT-qPCR). Total RNA was extracted from the tissue samples using TRIzol ${ }^{\circledR}$ 
Table I. Primer sequences.

\begin{tabular}{lll} 
Gene & \multicolumn{1}{c}{ Forward 5'-3' } & \multicolumn{1}{c}{ Reverse 5'-3' } \\
\hline GAPDH & GGAGTCAACGGATTTGGTCGTAT & AGCCTTCTCCATGGTGGTGAAGAC \\
BDNF & CACTCCGACCCCGCCCGCCG & TCCACTATCTTCCCCTTTTA \\
NF-אB & AATTGCCCCGGCAT & TCCCGTAACCGCGTA \\
\hline
\end{tabular}

BDNF, brain-derived neurotrophic factor.

reagent (Thermo Fisher Scientific, Inc.) and reverse transcribed using a High-Capacity cDNA Reverse Transcription kit (Thermo Fisher Scientific, Inc.) per the manufacturer's protocol. The primers for qPCR were designed by Primer Premier 6.0 (Premier Biosoft International) and synthetized by Invitrogen; Thermo Fisher Scientific, Inc. (Table I). qPCR was performed using SYBR Green (Thermo Fisher Scientific, Inc.) and the thermocycling conditions were as follows: 35 cycles at $92^{\circ} \mathrm{C}$ for $30 \mathrm{sec}, 58^{\circ} \mathrm{C}$ for $40 \mathrm{sec}$, and $72^{\circ} \mathrm{C}$ for $35 \mathrm{sec}$. The $2^{-\mathrm{DDCq}}$ method (16) was used to calculate relative expression levels in reference to GAPDH.

Western blotting. The sample tissues were lysed using RIPA buffer and quantified using a bicinchoninic acid assay. The proteins (40 $\mu \mathrm{g} /$ lane) were separated by SDS-PAGE using a $10 \%$ gel, and transferred to a PVDF membrane at $160 \mathrm{~mA}$ for $1.5 \mathrm{~h}$. The membrane was blocked with $5 \%$ skim milk at room temperature for $2 \mathrm{~h}$, and subsequently incubated with primary antibodies against BDNF (1:1,000; cat. no. ab226843), NF- $\mathrm{BB}(1: 1,500$; cat. no. ab16502) and $\beta$-actin $(1: 2,000$; cat. no. ab8227) at $4^{\circ} \mathrm{C}$ overnight. After washing three times with PBS-Tween, the membrane was incubated with a secondary horseradish peroxidase-conjugated antibody (1:5,000; cat. no. ab6721) at room temperature for $30 \mathrm{~min}$. The proteins were then visualized using ECL reagent. Each experiment was repeated four times and protein expression was quantified using Quantity One software (version 4.6.8; Bio-Rad Laboratories, Inc.).

Statistical analysis. All data analysis was performed using SPSS 19.0 software (IBM Corp.). The data are presented as the mean \pm standard deviation and compared by one-way ANOVA and Newman-Keuls multiple comparisons analysis. $\mathrm{P}<0.05$ was considered to indicate a statistically significant difference.

\section{Results}

The impact of methylprednisolone combined with high frequency electrotherapy on SCI rats. BBB score analysis was performed to evaluate the impact of methylprednisolone combined with high frequency electrotherapy on SCI rats. All treatment groups exhibited significantly elevated BBB scores compared with the untreated, SCI group $(\mathrm{P}<0.05)$. However, the combination group exhibited more significant effects on SCI $(\mathrm{P}<0.05$; Fig. 1). This suggested that methylprednisolone combined with high frequency electrotherapy improved the pathological process of SCI and promoted recovery.
The influence of methylprednisolone combined with high frequency electrotherapy on the SEPs and MEPS of SCI rats. SEPs and MEPs were analyzed to assess the influence of methylprednisolone combined with high frequency electrotherapy on SCI rats. All treatment groups displayed obviously improved SEPs and MEPs compared with the SCI group $(\mathrm{P}<0.05)$, though the combination group exhibited the most significant effects on SCI $(\mathrm{P}<0.05$; Table II). These results indicated that methylprednisolone combined with high frequency electrotherapy alleviated the pathological effects of SCI and promoted recovery.

BDNF $m R N A$ and protein expression levels in spinal cord tissues. RT-qPCR and western blotting were used to determine BDNF mRNA and protein expressions levels in the spinal cord tissues of rats. All treatment groups presented with markedly increased BDNF mRNA and protein expression levels compared with the SCI group $(\mathrm{P}<0.05)$. The combination group exhibited more significant effects on SCI $(\mathrm{P}<0.05)$ (Fig. 2 and 3).

$N F-\kappa B m R N A$ and protein expression levels in spinal cord tissues. RT-qPCR and western blot analysis were used to evaluate the expression levels of $\mathrm{NF}-\kappa \mathrm{B} \mathrm{mRNA}$ and protein in rat spinal cord tissues. The treatment groups showed considerably reduced expression levels of NF- $\mathrm{NB}$ mRNA and protein compared with the untreated, SCI group $(\mathrm{P}<0.05)$, and the combination group exhibited the most significant effects on SCI $(\mathrm{P}<0.05$; Fig. 4 and 5).

The effect of methylprednisolone combined with high frequency electrotherapy on serum TNF- $\alpha$ and IL-2 expression levels in SCI rats. The effects of methylprednisolone combined with high frequency electrotherapy on serum TNF- $\alpha$ and IL-2 expression level were assessed by ELISA. The treatment groups revealed a reduction in serum TNF- $\alpha$ and IL-2 expression levels compared with the SCI group $(\mathrm{P}<0.05)$; furthermore, the combination group exhibited a more significant effect on SCI $(\mathrm{P}<0.05$; Fig. 6) revealing that methylprednisolone combined with high frequency electrotherapy inhibited cytokine release, alleviating inflammatory damage.

The impact of methylprednisolone combined with high frequency electrotherapy on caspase 3 activity. Caspase 3 activity was detected in the spinal cord tissues. Each treatment group displayed significantly decreased caspase 3 activity compared with the SCI group $(\mathrm{P}<0.05)$. The combination group exhibited more significant effects on SCI $(\mathrm{P}<0.05$; Fig. 7), which collectively indicated that methylprednisolone combined with high frequency electrotherapy suppressed caspase 3 activity to regulate apoptosis. 


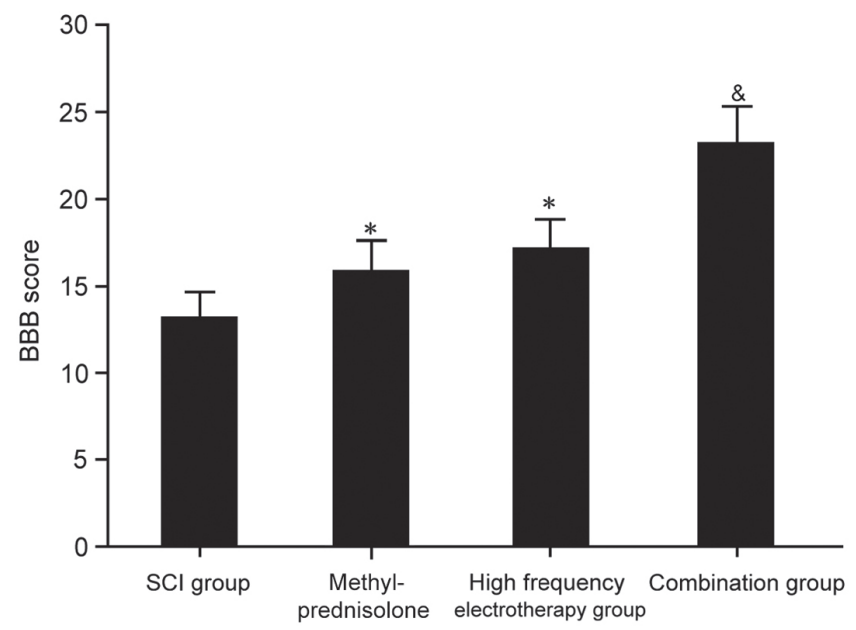

Figure 1. Impact of methylprednisolone combined with high frequency electrotherapy on the BBB scores of SCI rats. ${ }^{*} \mathrm{P}<0.05$ vs. the SCI group; ${ }^{\circledR} \mathrm{P}<0.05$ vs. the methylprednisolone group or high frequency electrotherapy group. BBB, Basso, Beattie and Bresnahan; SCI, spinal cord injury.

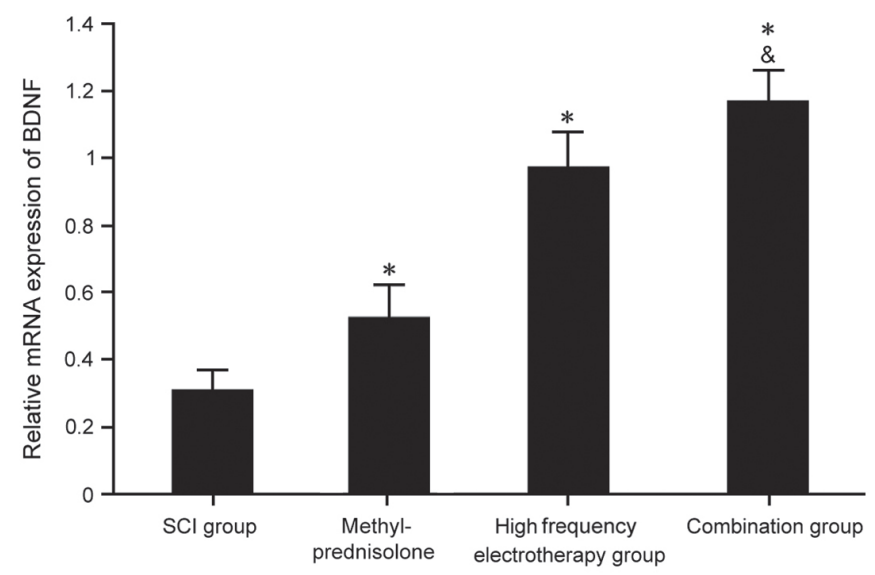

Figure 2. BDNF mRNA expression levels in the spinal cord tissues of SCI rats following treatment. ${ }^{*} \mathrm{P}<0.05$ vs. the SCI group; ${ }^{\text {P }} \mathrm{P}<0.05$ vs. the methylprednisolone or high frequency electrotherapy group. BDNF, brain-derived neurotrophic factor; SCI, spinal cord injury.

\section{Discussion}

With the rapid development of science and technology, the use of physics at a clinical level is able to significantly promote spinal nerve regeneration and improve the local microenvironment of the spinal cord. It has been confirmed that high-frequency microwave treatment is beneficial to nutritional axons, promoting regeneration at sites of peripheral nerve injury, accelerating tissue recovery and reducing pathological injury $(13,14)$. Conversely, the adrenal cortical hormone methylprednisolone has a strong anti-inflammatory effect that is conducive to recovery in the early stages of SCI $(15,17)$. Therefore, the present study aimed to investigate the effect of combined treatment with methylprednisolone and physical rehabilitation on SCI and its associated mechanisms.

The BBB scoring method is widely used to evaluate the degree of SCI (12), and SEPs and MEPs can effectively analyze the functional recovery degree of SCI. The present
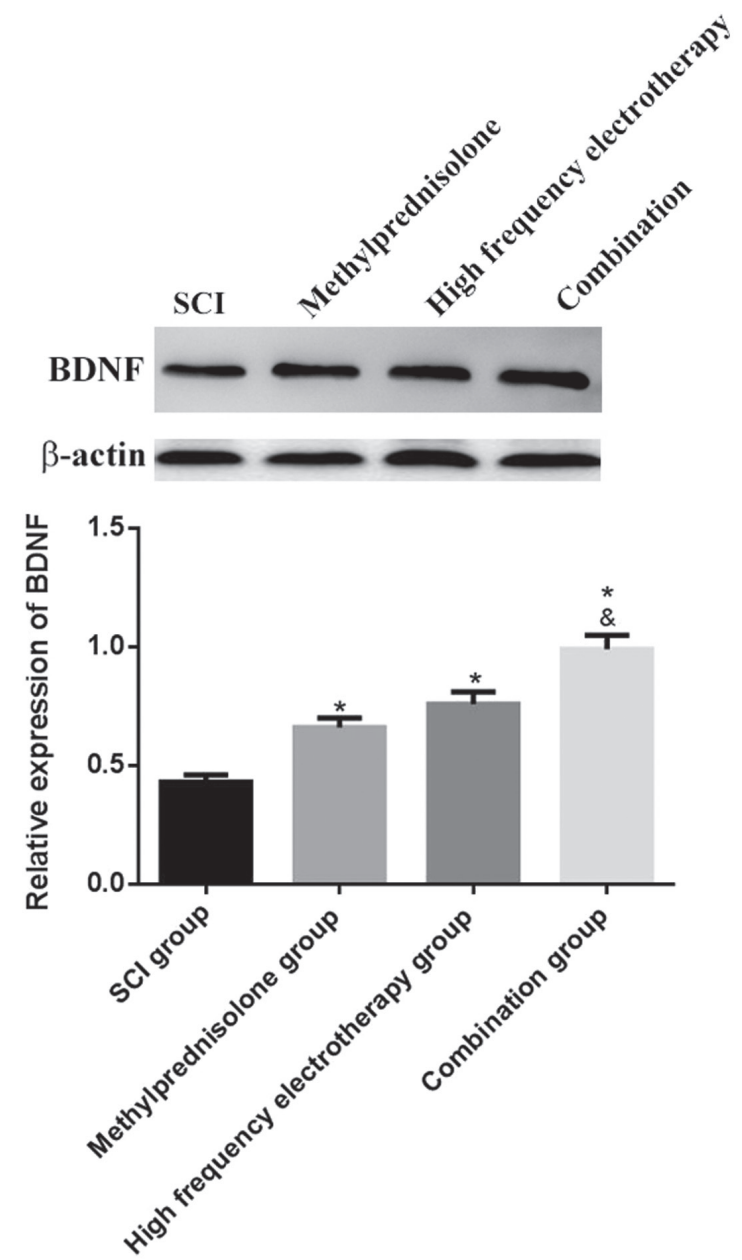

Figure 3. BDNF protein expression levels in the spinal cord tissues of SCI rats following treatment. " $\mathrm{P}<0.05$ vs. the SCI group; ${ }^{\circledR} \mathrm{P}<0.05$ vs. the methylprednisolone or high frequency electrotherapy group. BDNF, brain-derived neurotrophic factor; SCI, spinal cord injury.

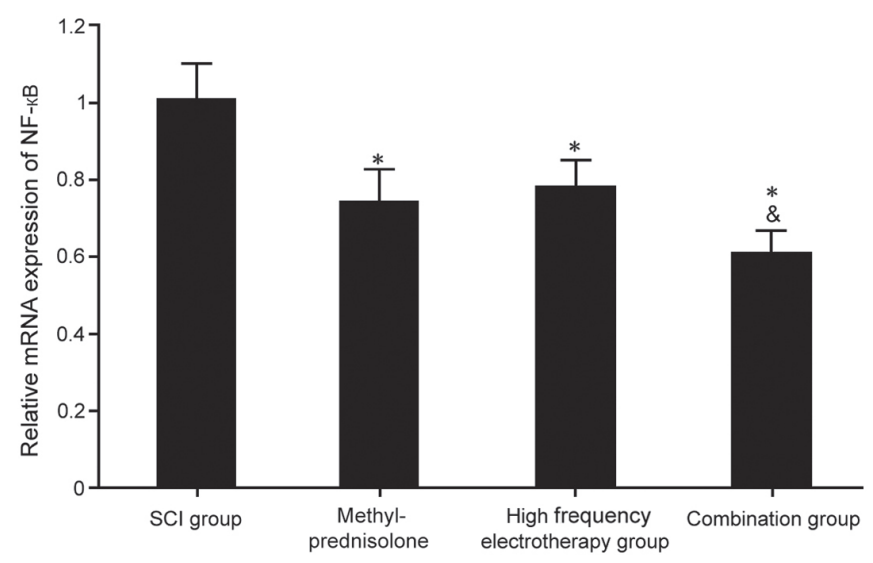

Figure 4. NF-kB mRNA expression levels in the spinal cord tissues of SCI rats following treatment. "P<0.05 vs. the SCI group; ${ }^{\mathrm{P}}<0.05$ vs. the methylprednisolone or high frequency electrotherapy group. SCI, spinal cord injury.

study revealed significantly increased BBB scores in the methylprednisolone, high-frequency electrotherapy and combination groups, in additional to elevated SEPs and MEPs. However, methylprednisolone combined with high-frequency treatment exhibited a greater significant influence on BBB 
Table II. Influence of methylprednisolone combined with high frequency electrotherapy.

\begin{tabular}{lccc}
\hline & \multicolumn{2}{c}{ SEP } & \multicolumn{1}{c}{ MEP } \\
\cline { 2 - 4 } Group & P1 incubation period, ms & N1 incubation period, ms & Incubation period, ms \\
\hline SCI & $42.12 \pm 2.24$ & $67.92 \pm 5.21$ & $14.81 \pm 1.47$ \\
High-frequency electrotherapy & $34.17 \pm 3.36^{\mathrm{a}}$ & $51.35 \pm 3.24^{\mathrm{a}}$ & $9.53 \pm 0.38^{\mathrm{a}}$ \\
Combination & $21.36 \pm 1.47^{\mathrm{b}}$ & $43.92 \pm 5.48^{\mathrm{b}}$ & $6.35 \pm 0.28^{\mathrm{b}}$ \\
\hline
\end{tabular}

${ }^{\mathrm{a}} \mathrm{P}<0.05 ;{ }^{\mathrm{b}} \mathrm{P}<0.01$. Combination treatment denotes methylprednisolone (300 $\left.\mathrm{mg} / \mathrm{kg}\right)$ combined with high-frequency electrotherapy. SEP, somatosensory evoked potential; MEP, motor evoked potential; SCI, spinal cord injury.

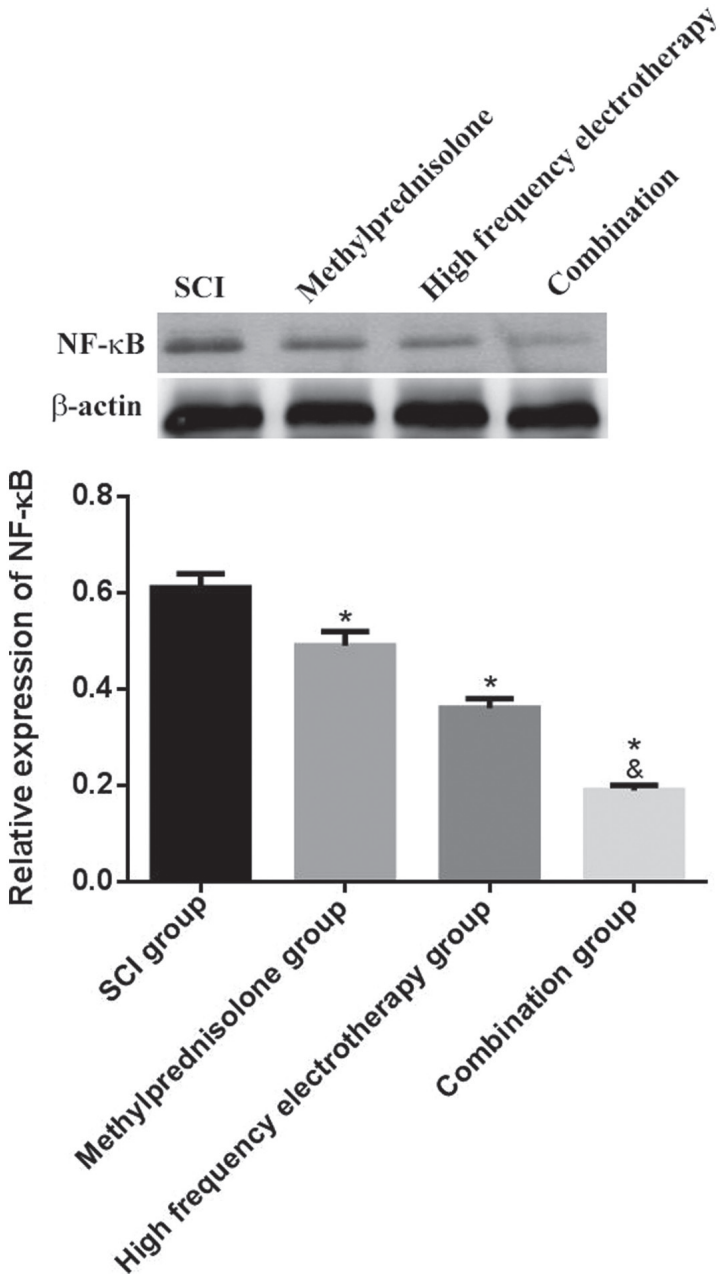

Figure 5. NF- $\mathrm{kB}$ protein expression levels in the spinal cord tissues of SCI rats following treatment. " $\mathrm{P}<0.05$ vs. the SCI group; ${ }^{\circledR} \mathrm{P}<0.05$ vs. the methylprednisolone or high frequency electrotherapy group. SCI, spinal cord injury.

score, SEPs and MEPs in SCI rats. These results suggested that high-frequency electrotherapy may effectively improve SCI, which may be associated with high-frequency electrotherapy waves promoting the movement, stretching, migration and swinging of membrane lipids and membrane proteins, strengthening metabolism and accelerate neuronal changes in the spinal cord $(18,19)$. Analysis of inflammatory factors revealed that both singular treatments were able to reduce serum TNF- $\alpha$ and IL-2 expression levels in SCI rats, but that

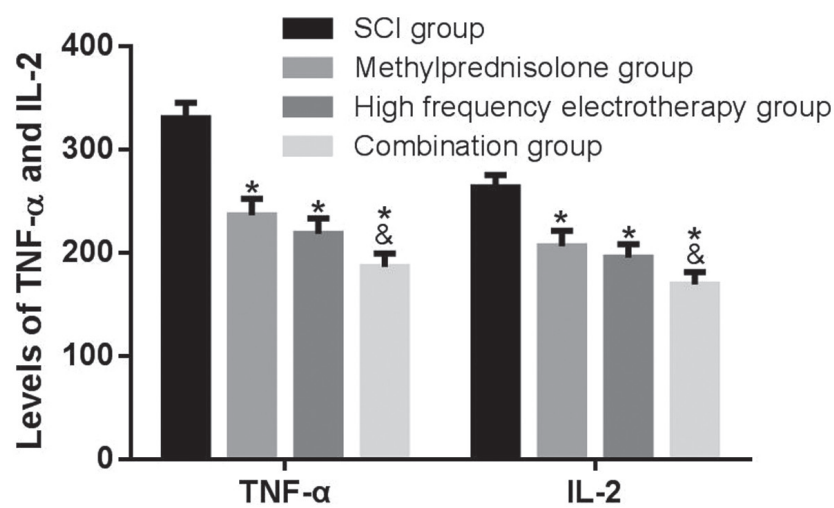

Figure 6. Effects of methylprednisolone combined with high frequency electrotherapy on serum TNF- $\alpha$ and IL-2 expression levels in SCI rats. ${ }^{*} \mathrm{P}<0.05$ vs. the $\mathrm{SCI}$ group; ${ }^{\&} \mathrm{P}<0.05$ vs. the methylprednisolone or high frequency electrotherapy group. SCI, spinal cord injury; TNF, tumor necrosis factor.

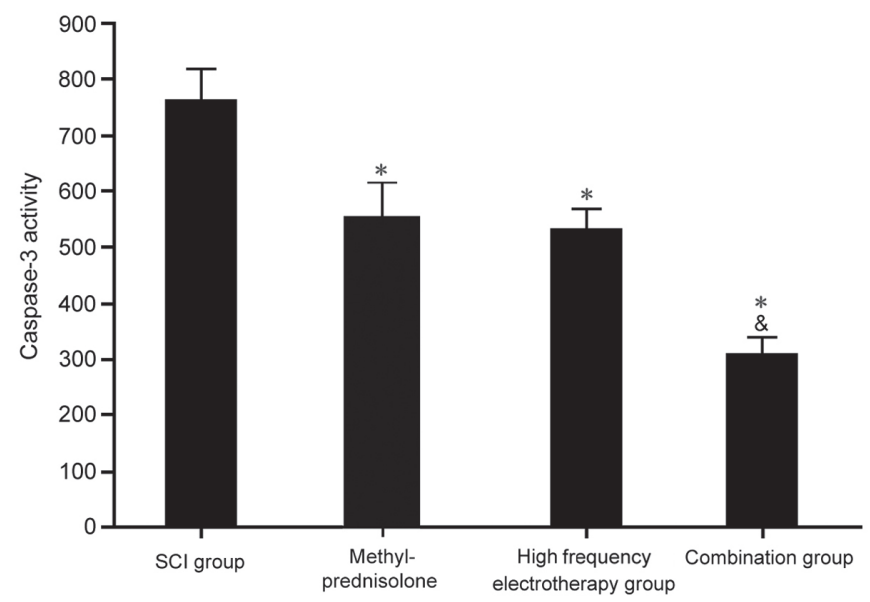

Figure 7. Impact of methylprednisolone combined with high frequency electrotherapy on Caspase 3 activity. ${ }^{*} \mathrm{P}<0.05$ vs. the $\mathrm{SCI}$ group; ${ }^{\circledR} \mathrm{P}<0.05$ vs. the methylprednisolone or high frequency electrotherapy group. SCI, spinal cord injury.

methylprednisolone treatment combined with high-frequency electrotherapy resulted in a more significant improvement, which may be associated with the marked inhibition of inflammation caused by methylprednisolone $(15,17)$. The combined effects of methylprednisolone effectively boosted the healing effects of high frequency electrotherapy on SCI. 
Neurotrophin family member BDNF promotes the growth and survival of sensory and motor nerves, thus serves an important role in nerve regeneration $(20,21)$. Activation of NF- $\mathrm{kB}$ during SCI promotes neutrophil accumulation and macrophage adhesion, leading to the release of a large number of oxygen free radicals; this promotes the secretion of inflammatory cytokines such as TNF- $\alpha$ and IL-2, and subsequently compromises the integrity of spinal cord tissue by inducing vascular endothelial deterioration, increasing edema and necrosis of the spinal cord tissue, and promoting secondary SCI $(22,23)$. Caspase 3 is a critical protease in apoptosis and is also the common downstream target of each apoptotic pathway (24). In the present study, the methylprednisolone, high-frequency electrotherapy and combination groups exhibited significantly increased expression levels of BDNF mRNA and protein, reduced NF- $\mathrm{KB}$ mRNA and protein expression levels, and a reduction in caspase 3 activity. The combination group exhibited the greatest effects on SCI.

The present study aimed to analyze the mechanisms and subsequent effects of methylprednisolone treatment combined with rehabilitation high-frequency electrotherapy on SCI, and to further verify the relevant roles and mechanisms observed in clinical trials. In conclusion, methylprednisolone combined with high frequency electrotherapy was able to improve SCI, possibly by increasing BDNF and decreasing NF- $\kappa \mathrm{B}$ expression levels, in addition to suppressing the release of inflammatory factors.

\section{Acknowledgements}

Not applicable.

\section{Funding}

No funding was received.

\section{Availability of data and materials}

The datasets used and/or analyzed during the current study are available from the corresponding author on reasonable request.

\section{Authors' contributions}

SL, CL, WW, LL and QZ performed the experiments and analyzed the data. YO designed the study and wrote the manuscript. All authors read and approved the final manuscript.

\section{Ethics approval and consent to participate}

All procedures were approved by the Animal Ethics Committee of The First Affiliated Hospital of Xi'an Medical University.

\section{Patient consent for publication}

Not applicable.

\section{Competing interests}

The authors declare that they have no competing interests.

\section{References}

1. Burkovskiy I,Zhou J and Lehmann C: Experimental cannabinoid 2 receptor inhibition in CNS injury-induced immunodeficiency syndrome. Microcirculation 23: 283-292, 2016.

2. Cheah M, Andrews MR, Chew DJ, Moloney EB, Verhaagen J, Fässler R and Fawcett JW: Expression of an activated integrin promotes long-distance sensory axon regeneration in the spinal cord. J Neurosci 36: 7283-7297, 2016.

3. Fang H, Zhang JC, Yang M, Li HF, Zhang JP, Zhang FX, Wang QY, Wang RR and Liu J: Perfusion of gastrodin in abdominal aorta for alleviating spinal cord ischemia reperfusion injury. Asian Pac J Trop Med 9: 688-693, 2016.

4. Qin W, Li X, Peng Y, Harlow LM, Ren Y, Wu Y, Li J, Qin Y, Sun J, Zheng S, et al: Sclerostin antibody preserves the morphology and structure of osteocytes and blocks the severe skeletal deterioration after motor-complete spinal cord injury in rats. J Bone Miner Res 31: 1482, 2016.

5. Rao SN and Pearse DD: Pearse, regulating axonal responses to injury: The intersection between signaling pathways involved in axon myelination and the inhibition of axon regeneration. Front Mol Neurosci 9: 33, 2016

6. Harsha KJ and Parameswaran K: Permanent spinal cord injury during lumbar spinal anesthesia: A report of two cases. Neurol India 64: 808-811, 2016.

7. Nunnerley J, Gupta S, Snell D and King M: Training wheelchair navigation in immersive virtual environments for patients with spinal cord injury-end-user input to design an effective system. Disabil Rehabil Assist Technol 12: 417-423, 2017.

8. Sachdeva R, Farrell K, McMullen MK, Twiss JL and Houle JD: Dynamic changes in local protein synthetic machinery in regenerating central nervous system axons after spinal cord injury. Neural Plast 2016: 4087254, 2016.

9. Haik MN, Alburquerque-Sendín F, Moreira RF, Pires ED and Camargo PR: Effectiveness of physical therapy treatment of clearly defined subacromial pain: A systematic review of randomised controlled trials. Br J Sports Med 50: 1124-1134, 2016.

10. Page MJ, Green S, Mrocki MA, Surace SJ, Deitch J, McBain B, Lyttle N and Buchbinder R: Electrotherapy modalities for rotator cuff disease. Cochrane Database Syst Rev CD012225, 2016.

11. D'Angelo R, Morreale A, Donadio V, Boriani S, Maraldi N, Plazzi G and Liguori R: Neuropathic pain following spinal cord injury: What we know about mechanisms, assessment and management. Eur Rev Med Pharmacol Sci 17: 3257-3261, 2013.

12. Braughler JM and Hall ED: Effects of multi-dose methylprednisolone sodium succinate administration on injured cat spinal cord neurofilament degradation and energy metabolism. J Neurosurg 61: 290-295, 1984.

13. Bi X, Lv H, Chen BL, Li X and Wang XQ: Effects of transcutaneous electrical nerve stimulation on pain in patients with spinal cord injury: A randomized controlled trial. J Phys Ther Sci 27: 23-25, 2015.

14. Phillips AA, Matin N, Frias B, Zheng MM, Jia M, West C, Dorrance AM, Laher I and Krassioukov AV: Rigid and remodelled: Cerebrovascular structure and function after experimental high-thoracic spinal cord transection. J Physiol 594: 1677-1688, 2016.

15. Rabchevsky AG, Fugaccia I, Sullivan PG, Blades DA and Scheff SW: Efficacy of methylprednisolone therapy for the injured rat spinal cord. J Neurosci Res 68: 7-18, 2002.

16. Livak KJ and Schmittgen TD: Analysis of relative gene expression data using real-time quantitative PCR and the 2(-Delta Delta C(T)) method. Methods 25: 402-408, 2001.

17. Hextrum $S$ and Bennett $S$ : A Critical examination of subgroup analyses: The national acute spinal cord injury studies and beyond. Front Neurol 9: 11, 2018.

18. Abnoosian A and Maguire G: Case report of an interaction of a vagal nerve stimulation system with a microwave current from a body fat analyzer. Ann Clin Psychiatry 20: 229-230, 2008.

19. von Bary C, Mazzitelli D, Voss B, Kübler F, Schmeller ML, Ndrepepa G and Zrenner B: Evaluation of epicardial microwave lesions in the pig model using an electroanatomic mapping system. J Interv Card Electrophysiol 22: 5-11, 2008.

20. Man L, Lv X, Du XD, Yin G, Zhu X, Zhang Y, Soares JC, Yang XN, Chen $X$ and Zhang XY: Cognitive impairments and low BDNF serum levels in first-episode drug-naive patients with schizophrenia. Psychiatry Res 263: 1-6, 2018. 
21. Sapkota S and Dixon RA: A network of genetic effects on non-demented cognitive aging: Alzheimer's genetic risk (CLU + CR1 + PICALM) intensifies cognitive aging genetic risk (COMT + BDNF) selectively for APOe4 carriers. J Alzheimers Dis 62: 887-900, 2018

22. Chen BH, Park JH, Lee TK, Song M, Kim H, Lee JC, Kim YM, Lee CH, Hwang IK, Kang IJ, et al: Melatonin attenuates scopolamine-induced cognitive impairment via protecting against demyelination through BDNF-TrkB signaling in the mouse dentate gyrus. Chem Biol Interact 285: 8-13, 2018.

23. Hanada M, Tsutsumi K, Arima H, Shinjo R, Sugiura Y, Imagama S, Ishiguro $\mathrm{N}$ and Matsuyama Y: Evaluation of the effect of tranilast on rats with spinal cord injury. J Neurol Sci 346: 209-215, 2014.
24. Liu YH, Liu GH, Mei JJ and Wang J: The preventive effects of hyperoside on lung cancer in vitro by inducing apoptosis and inhibiting proliferation through caspase- 3 and P53 signaling pathway. Biomed Pharmacother 83: 381-391, 2016.

This work is licensed under a Creative Commons Attribution-NonCommercial-NoDerivatives 4.0 International (CC BY-NC-ND 4.0) License. 